\title{
Optimal Design of Large Circular Vibrating Screen Based on Multiple Frequencies Constraints and Analytical Sensitivity Methods
}

\author{
Jun-Xia Yan ${ }^{*}{ }^{1,2}$, Qing-Zhong Li ${ }^{1,2}$, Li-Guo Liu ${ }^{1,2}$ and Shan-Hua Qian ${ }^{1,2}$ \\ ${ }^{I}$ School of Mechanical Engineering, Jiangnan University, Wuxi 214122, Jiangsu, China \\ ${ }^{2}$ Jiangsu Key Laboratory of Advanced Food Manufacturing Equipment and Technology (Jiangnan University), Wuxi \\ 214122, Jiangsu, China
}

\begin{abstract}
Multiple frequencies constraints and analytical sensitivity methods were used in the structural optimization design of the side plate of 4YK1860 vibrating screen to reduce the damage of side plate caused by high dynamic stress. The mass of side plate of the vibrating screen was taken as object function, mode frequencies were regarded as state parameters, size of the plate was used as the constraint parameter and an optimization criterion which is applicable to solve this kind of problem was given. Meanwhile, sensitivity characteristics of variable parameters were considered during the process of optimization. The results show that the optimization program with embedded analytical sensitivity calculation methods is of a higher solving precision and with a more stable calculating process. After structure optimization, the thickness of side plate to withstand large impact is increased, the thickness of stiffener and peripheral angle is decreased, the mass of side plate is reduced by $7.75 \%$ and a better optimization effect is achieved. The analysis of the optimal vibrating screen presents that the mass of vibrating screen decreases by $3.5 \%$, elastic deformation frequency which is close to the working frequency increases by $8.8 \%$ and the dynamic stress decreases by $48 \%$. The natural frequencies of vibrating screen are improved and modal frequency is far from the working frequency of the exciting motor, stress concentration of vibrating screen is weakened and thus the structural stiffness and reliability of vibrating screen are enhanced.
\end{abstract}

Keywords: Analytical sensitivity, Large circular vibrating screen, Multiple frequencies constraints, Optimum design.

\section{INTRODUCTION}

Side plate and beam of vibrating screen reach the fatigue limit of their material always more quickly than the other parts. It can be found that in practical engineering, with the vibrating screen scrap, the most damaged parts are the side plate and the beam [1]. Another common fatigue failure appears on stress concentration points of the vibrating screen, for instance, joint part of bearing, spring box, welded area, etc. The side plate and beam of vibrating screen bear large inertial force besides the exciting force being in the operating condition. The screen body does not have rigid vibration but has elastic vibration in working frequency. It produces large dynamic stress on the beam and side plate when the screen body is in elastic vibration condition and the stress concentration results in dynamic response. So it appears as a fatigue failure in the structure of the beam and side plate [2-4]. According to the problem stated above, the aim of the large vibrating screen optimization is to have reasonable structure improvements, enhanced fatigue strength, decreased dynamic stress and extended service life of vibrating screen. Therefore, structural dimension optimization of large circular vibrating screen 4YK1860 has been studied in this paper based on multiple frequencies

*Address correspondence to this author at the School of Mechanical Engineering, Jiangnan University, Wuxi 214122, Jiangsu, China; Tel: 008618921516059; E-mail: yjx@jiangnan.edu.cn constraints and analytical sensitivity methods and the optimal structure of vibrating screen was obtained.

\section{ANALYTICAL SENSITIVITY METHOD}

Structure parameters that have the most effect on the system in the process of structure optimization can be found by sensitivity analysis, thus improving the optimization efficiency. The general optimization design software uses difference method and semi-analytical method to calculate the sensitivity. These two methods affect the difference step and increase the time taken for optimization analysis which reduces the computational efficiency; moreover, the optimization results are not obvious. According to references [5-7], the analytical formulas of sensitivity based on objective function and constraint conditions are put forward. The mass of structure is the objective function with frequency as the main form of constraint. Analytical sensitivity method of objective function is given as:

$$
\frac{\partial W}{\partial p_{i}}=\frac{\partial \sum w^{e}}{\partial p_{i}}=\sum \frac{\partial w^{e}}{\partial p_{i}}
$$

where, $W$ expresses objective function, $w^{e}$ expresses element mass and $p_{i}$ expresses design variable. The method of analytical sensitivity with constraints is:

$$
\frac{\partial \lambda_{r}}{\partial p_{i}}=\phi_{r}^{T}\left(\frac{\partial K}{\partial p_{i}}-\lambda_{r} \frac{\partial M}{\partial p_{i}}\right)\left\{\phi_{r}\right\}
$$


$\frac{\partial \lambda_{r}}{\partial p_{i}}=\phi_{r}^{T}\left(\sum \frac{\partial k^{e}}{\partial p_{i}}-\lambda_{r} \frac{\partial m^{e}}{\partial p_{i}}\right)\left\{\phi_{r}\right\}$

In which, $\lambda_{r}$ expresses frequency constraints, $\phi_{r}$ expresses modal of corresponding frequency, $K$ expresses general stiffness matrix, $M$ expresses general mass matrix, $k^{e}$ expresses element stiffness matrix, $m^{e}$ expresses element mass matrix.

Both the formulas (2) and (3) can be used to calculate the analytical sensitivity, but the method of formula (2) requires assembling partial derivative matrix of design variables about general stiffness matrix and general mass matrix, so a long calculation time and more storage space are needed. According to formula (3), partial derivative of design variables regarding relevant element stiffness matrix and mass matrix initially can be calculated, followed by calculating the contribution that the relevant element makes to frequency sensitivity and finally superimposes the contribution of element to obtain frequency sensitivity. In this way, it omits the multiplication and assembly of large matrix, helps save storage space and improves the computational efficiency.

It can be known from formula (3) that partial derivative of element stiffness matrix and element mass matrix need to be calculated when calculating the frequency sensitivity of the structure. If this function is put in the program of structure optimization analysis, it can calculate the partial derivative matrix of element stiffness matrix and element mass matrix simultaneously by structure analysis.

\section{OPTIMAL PARAMETERS DETERMINATION OF CIRCULAR VIBRATING SCREEN}

Before the optimization of the vibrating screen side plate, the optimal parameters of the structure of side plate need to be determined. The structure of side plate with stiffeners, angle stiffeners, mounting hole of shaft and vibration exciter is very complex. Taking the least weight as objective function, frequency optimization problem can be formulated [8].

Objective function:

$\min w(x)=\sum_{i=1}^{n} \rho_{i} x_{i} l_{i}$

Behavior constraint:

$g_{j}(x)=G_{j}(x)-\bar{G}_{j} \leq 0(j=1,2, \cdots, m)$

Dimension constraint:

$x_{i}^{l} \leq x_{i} \leq x_{i}^{u}(i=1,2, \cdots, n)$

where, $x$ expresses vector containing $\mathrm{n}-x_{i}, \rho_{i}$ expresses density, $x_{i}$ expresses design variable, $l_{i}$ expresses element length, $G_{j}(x)$ expresses vector of deflection, stress and frequency, $\dot{G}_{j}$ expresses limit value $G_{j}(x)$ needs to meet, $x_{i}^{l}$ and $x_{i}^{u}$ express upper and lower limits of element dimensions respectively.
Side thickness $h_{1}$, thickness of angle around side plate $h_{2}$, and stiffener width $b$ are taken as design variables of objective function in the optimization process. The initial

values of $h_{1}, h_{2}$ and $b$ are $15 \mathrm{~mm}, 15 \mathrm{~mm}$ and $100 \mathrm{~mm}$, respectively. The constraints of the design variables are given below.

$8 \mathrm{~mm} \leq h_{1} \leq 20 \mathrm{~mm} ; 6 \mathrm{~mm} \leq h_{2} \leq 20 \mathrm{~mm} ;$

$50 \mathrm{~mm} \leq b \leq 150 \mathrm{~mm}$

In order to meet the mechanical structural reliability, modal frequency is taken as constraint considering the dynamic characteristics of vibrating screen. So the first three modal frequencies $f_{1}, f_{2}$ and $f_{3}$ are taken as constraints which are obtained by inherent characteristic analysis of vibrating screen side plate before optimization. $f_{1}=7.83 \mathrm{~Hz}$, $f_{2}=10.21 \mathrm{~Hz}, f_{3}=15.20 \mathrm{~Hz}$ and constraints are set below.

$3.5 \mathrm{~Hz} \leq f_{1} \leq 8 \mathrm{~Hz} ; 8 \mathrm{~Hz} \leq f_{2} \leq 11 \mathrm{~Hz} ; 15 \mathrm{~Hz} \leq f_{3} \leq 20 \mathrm{~Hz}$

The optimization objective function is mass of side plate with the initial value as $1780 \mathrm{Kg}$.

\section{OPTIMIZATION CRITERIA}

Formula (5) can be expressed as below from multifrequency constraints aspects $[9,10]$.

$g_{j}(x)=\left(f_{j}^{2}-\alpha_{j} \bar{f}_{0}^{2}\right) \leq 0$

where, $\bar{f}_{0}$ expresses initial base frequency, $\alpha_{j} \bar{f}_{0}^{2}$ expresses square of $f_{j}$ which is $j$ order expected frequency. Characteristic equation of formula above is this.

$\left\{\Psi_{j}\right\}^{T}[K]\left\{\Psi_{j}\right\}-f_{j}^{2}\left\{\Psi_{j}\right\}^{T}[M]\left\{\Psi_{j}\right\}=0$

Element stiffness matrix $\left[K^{e}\right]$ and element mass matrix $\left[M^{e}\right]$ can be expressed as below considering nonlinear characteristics of the structure [11].

$\left[K^{e}\right]_{i}=\left[K^{e}\right]_{i}^{(0)}+x_{i}\left[K^{e}\right]_{i}^{(1)}+x_{i}^{2}\left[K^{e}\right]_{i}^{2}+\ldots$

$\left[M^{e}\right]_{i}=\left[M^{e}\right]_{i}^{(0)}+x_{i}\left[M^{e}\right]_{i}^{(1)}$

Taking complex formulas from (8) to (10), following can be obtained

$G_{i j}=\{\tilde{\Psi}\}^{T}\left([K]_{i}^{(1)}+2 x_{i}[K]_{i}^{(2)}-f_{j}^{2}[M]_{i}^{(1)}\right)\{\tilde{\Psi}\}$

where, $\{\tilde{\Psi}\}$ expresses modal vector of mass matrix $[M]$ after standardization.

Combining optimized parameters to build Lagrange equation.

$L(x, \varsigma)=\sum_{i=1}^{n} \rho_{i} x_{i} l_{i}-\sum_{j=1}^{m} \varsigma_{j}\left(f_{j}^{2}-\alpha_{j} \bar{f}_{0}^{2}\right)$

where, $\varsigma$ expresses Lagrange operator. 
Table 1. Optimization results of structure.

\begin{tabular}{|c|c|c|c|c|c|c|c|}
\hline Set2 & 8.61 & 9.81 & 16.62 & 17.86 & 12.40 & 88.80 & 1841.1 \\
\hline Set3 & 8.04 & 9.15 & 14.75 & 15.69 & 13.52 & 111.8 & 1673.0 \\
\hline Set5 & 5.88 & 8.03 & 10.03 & 10.48 & 17.10 & 108.2 & 1196.6 \\
\hline Set6 & 8.02 & 9.07 & 15.08 & 16.09 & 13.14 & 64.66 & 1647.4 \\
\hline Set7 & 7.97 & 9.03 & 15.11 & 16.15 & 12.32 & 62.92 & 1646.9 \\
\hline Set8 & 3.78 & 9.38 & 11.68 & 16.22 & 8.494 & 53.73 & 1624.6 \\
\hline
\end{tabular}

Differentiating formula (12) for $x_{i}$, and calculating the minimum value of $L$, the optimization criteria can be expressed as

$1=\sum_{j=1}^{m} \varsigma_{j} \frac{G_{i j}}{x_{i}^{2} \rho_{i} l_{i}}(i=1,2, \ldots, n)$

Making $\phi_{i}=\sum_{j=1}^{m} \varsigma_{j} \frac{G_{i j}}{x_{i}^{2} \rho_{i} l_{i}}$, the optimize recursive formula can be obtained.

$\left(x_{i}\right)_{r+1}=\left(x_{i}\right) r\left[1+\frac{1}{v}\left(\phi_{i}-1\right)\right]_{r}$

where, $r$ expresses cycles and $v$ expresses the step factor.

Solving method of $\zeta_{j}$ is complex given by N. S. Khot in reference [12]. Here, an approximate formula is proposed which meets the computing requirements through revised parameters and simplifies the small factor.

$\varsigma_{j}=\frac{W}{f_{j}^{2}\left(1-\xi_{j}\right)}$

where, $\quad W=\sum_{j=1}^{m} \rho_{i} x_{i} l_{i}+w^{*}, w^{*}$ expressing element fluctuation mass, $\xi_{j}=\frac{\left\{\Psi_{j}\right\}^{T}[M]_{s}\left\{\Psi_{j}\right\}}{\left\{\Psi_{j}\right\}^{T}[M]\left\{\Psi_{j}\right\}}$

\section{ANALYSIS OF OPTIMIZATION RESULTS}

\section{Side Plate Optimization Results}

Final optimization results obtained after nine iterations are shown in Table $\mathbf{1}$. The results of the ninth sequence shown in Table $\mathbf{1}$ are optimum, and the objective mass $m_{\mathrm{t}}$ is changed to $1642 \mathrm{Kg}$ from $1799 \mathrm{Kg}$.

Optimization process of objective $m_{\mathrm{t}}$ is shown in Fig. (1). Optimization process of side plate thickness $h_{1}$, angle thickness $h_{2}$, and stiffeners width are shown in Figs. (2-4). Optimization processes of constraints frequency $f_{1}, f_{2}$ and $f_{3}$ are shown in Figs. (5-7) respectively.

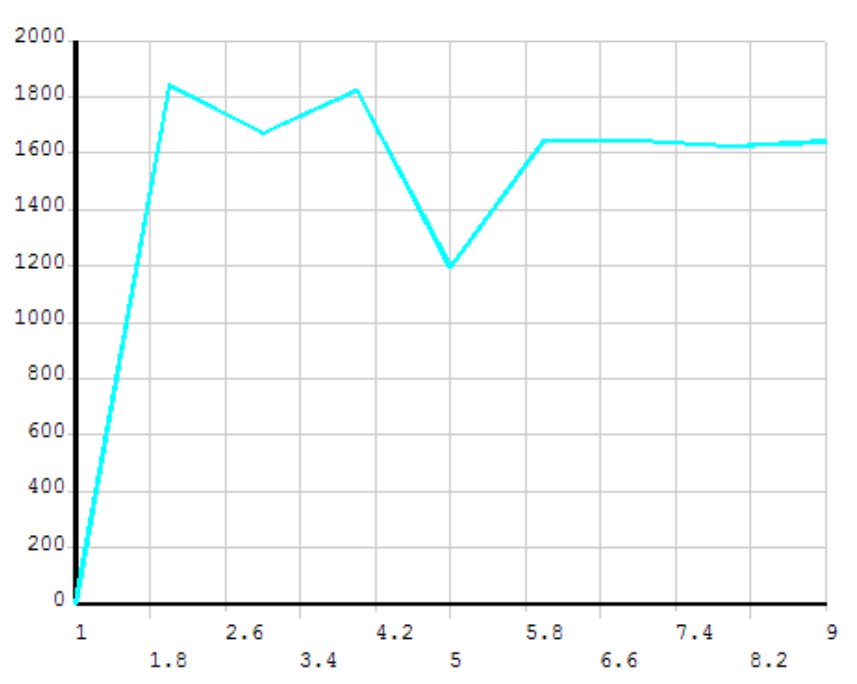

Fig. (1). Optimization process of $m_{\mathrm{t}}$.

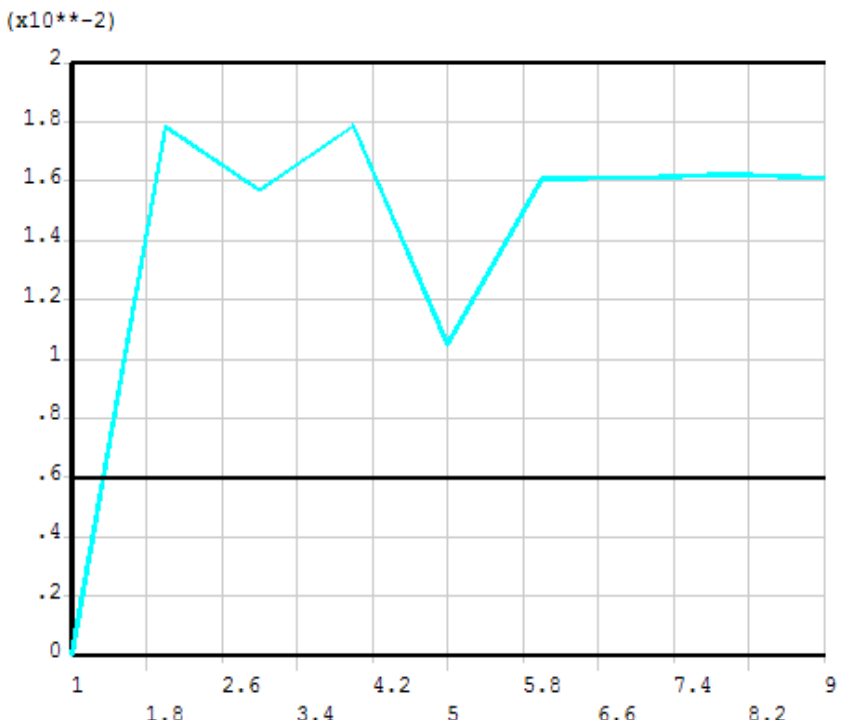

Fig. (2). Optimization process of $h_{1}$. 


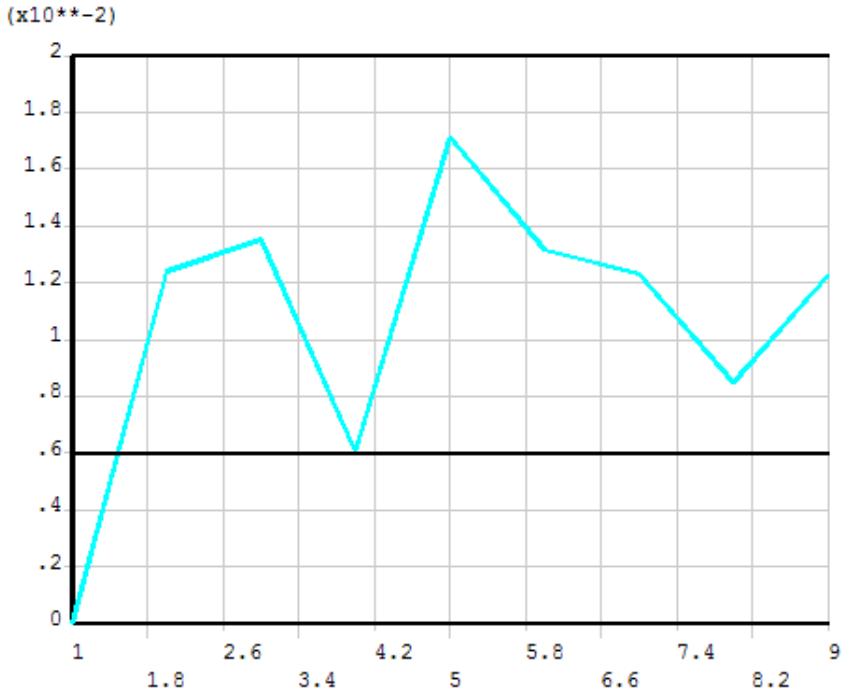

Fig. (3). Optimization process of $h_{2}$.

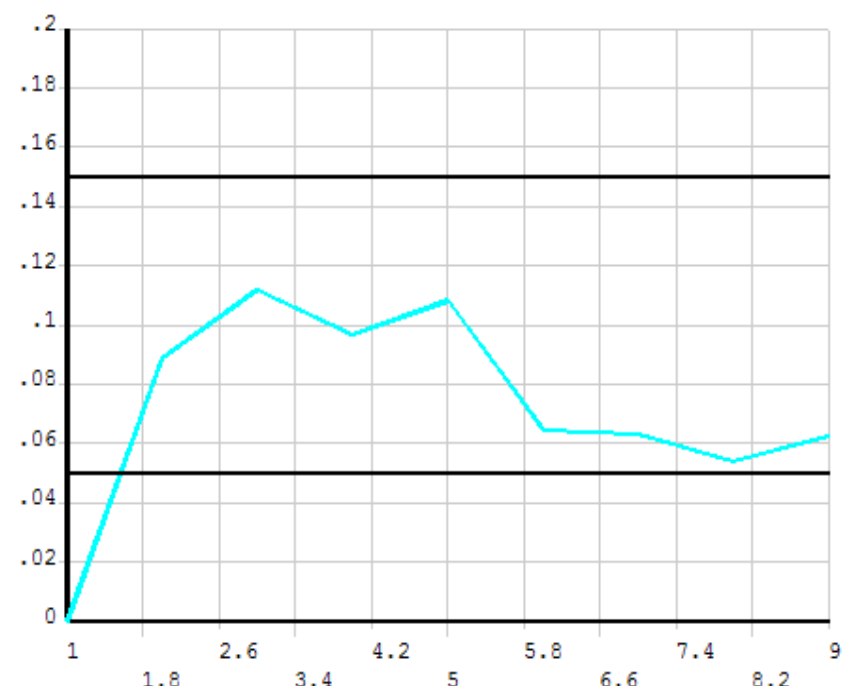

Fig. (4). Optimization process of $b$.

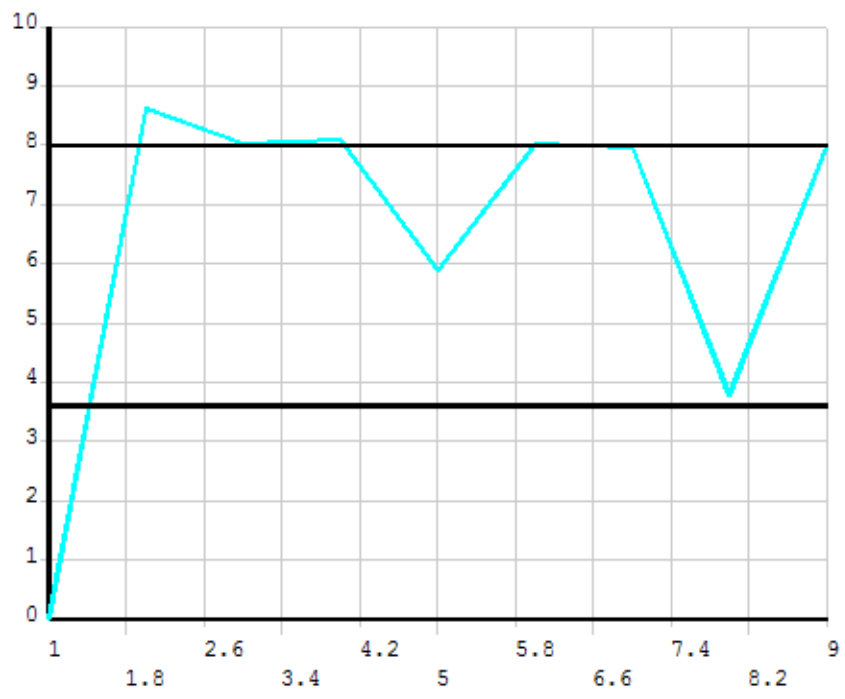

Fig. (5). Optimization process of $f_{1}$.

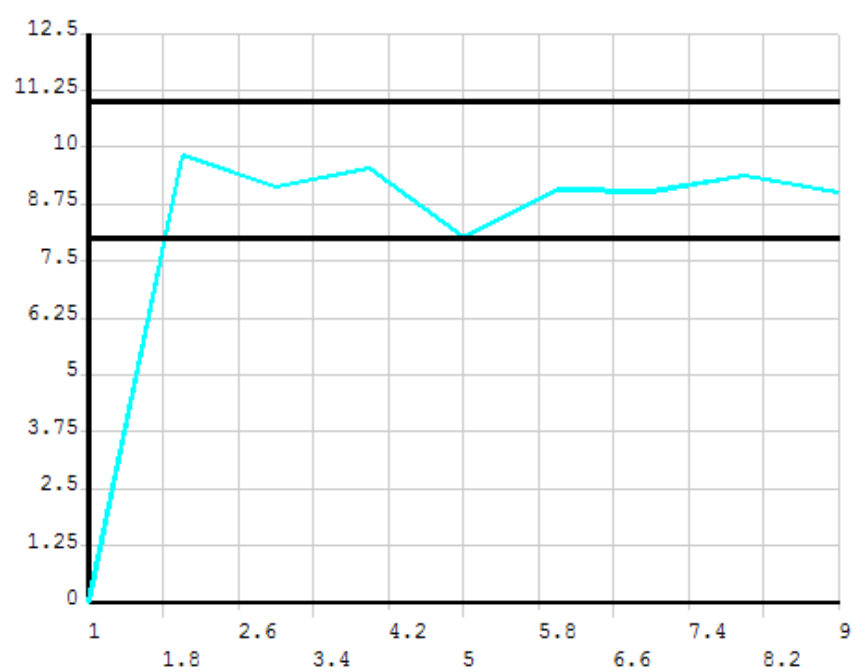

Fig. (6). Optimization process of $f_{2}$.

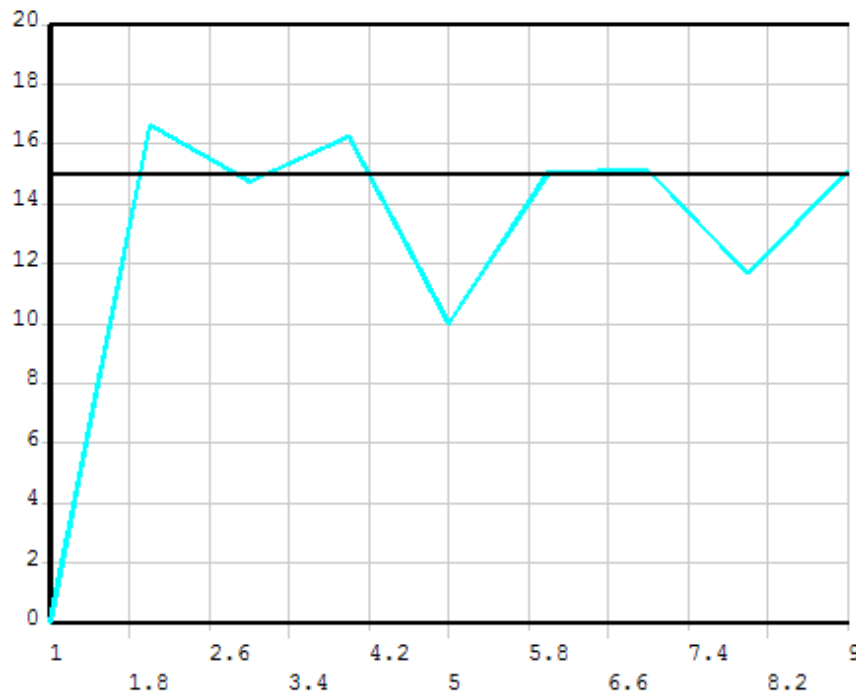

Fig. (7). Optimization process of $f_{3}$.

Table 2. Parameter optimization results comparison.

\begin{tabular}{|c|c|c|c|}
\hline Model Parameters & Before & After & Change Range/\% \\
\hline \hline$f_{1} / \mathrm{Hz}$ & 7.83 & 7.9614 & 1.67 \\
\hline$f_{2} / \mathrm{Hz}$ & 10.21 & 9.0158 & 11.6 \\
\hline$f_{3} / \mathrm{Hz}$ & 15.20 & 15.067 & 0.9 \\
\hline$h_{1} / \mathrm{mm}$ & 15 & 16.105 & 7.3 \\
\hline$h_{2} / \mathrm{mm}$ & 15 & 12.228 & 2.772 \\
\hline$b / \mathrm{mm}$ & 100 & 62.741 & 37.2 \\
\hline$m_{\mathrm{t}} / \mathrm{kg}$ & 1780 & 1642 & 7.75 \\
\hline
\end{tabular}

Comparison of the results before and after optimization in Table 2 shows that the side plate has a 7.75\% mass reduction and all parameters have obvious change. The first order frequency increases by $1.67 \%$ meanwhile the second and third order frequency decreases by $11.6 \%$ and $0.9 \%$ respectively. Thickness of side plate increases by $7.3 \%$ based 
on $15 \mathrm{~mm}$, thickness of angle iron around side plate decreases by $2.772 \%$, and the thickness of the stiffener reduces to $63 \mathrm{~mm}$ from $100 \mathrm{~mm}$. Overall, it achieves the desired objectives and ensures natural frequency having little change.

\section{Evaluation and Analysis of Vibrating Screen After Optimization}

\section{Results of Natural Mode Before and After Model Modification}

Fig. (8) shows the modified structure of the vibrating screen according to the optimization results. The results of dynamical analysis performed again and the first ten natural frequencies and natural mode of the vibrating screen calculated are shown in Table $\mathbf{3}$.

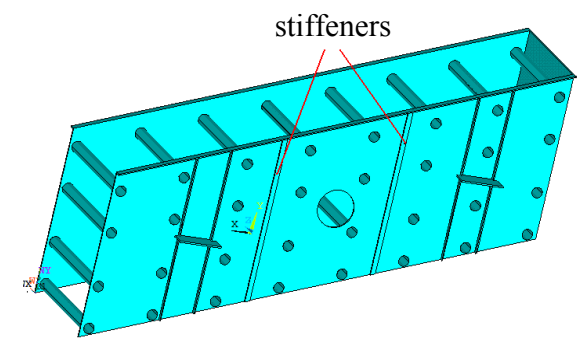

Fig. (8). Structure model.

Table 3. Model Shapes of new model.

\begin{tabular}{|c|c|l|}
\hline Order & Frequency/Hz & \multicolumn{1}{|c|}{ Modes } \\
\hline \hline 1 & 0.75149 & Rigid rotation around $z$ axis \\
\hline 2 & 1.4068 & Rigid translation along $x$ direction \\
\hline 3 & 2.9427 & $\begin{array}{l}\text { Rigid rotation of feed end and discharge } \\
\text { end around centroid axis }\end{array}$ \\
\hline 4 & 4.1851 & Rigid translation along $y$ direction \\
\hline 5 & 5.2309 & Rigid rotation around $x$ axis \\
\hline 6 & 22.668 & $\begin{array}{l}\text { Anisotropic torsion vibration of } \\
\text { side plates in } x y \text { plane }\end{array}$ \\
\hline 7 & 30.686 & $\begin{array}{l}\text { Reciprocating swing of feed end and } \\
\text { discharge end along } z \text { direction }\end{array}$ \\
\hline 8 & 35.034 & $\begin{array}{l}\text { Anisotropic swing of side plates } \\
\text { along } x \text { direction }\end{array}$ \\
\hline 9 & 50.083 & Fluctuation of screen box along $z$ direction \\
\hline 10 & 61.237 & $\begin{array}{l}\text { Reciprocating swing of side plates } \\
\text { along } z \text { direction }\end{array}$ \\
\hline
\end{tabular}

As shown in Table 3 below, frequencies of rigid vibration have a little change, having no effect on the dynamic characteristics. There is great increment in frequencies of bending deformation, and the ninth order frequency increases by nearly $30 \%$, which shows that the overall stiffness of vibrating screen increases. The sixth order frequency which is close to the working frequency 16.7 Hz impacts on deformation greatly and it changes from $20.834 \mathrm{~Hz}$ to $22.668 \mathrm{~Hz}$. The sixth order vibrating mode after optimization is shown in Fig. (9), and the displacement of vibration $D m x$ is $0.31 \mathrm{~mm}$

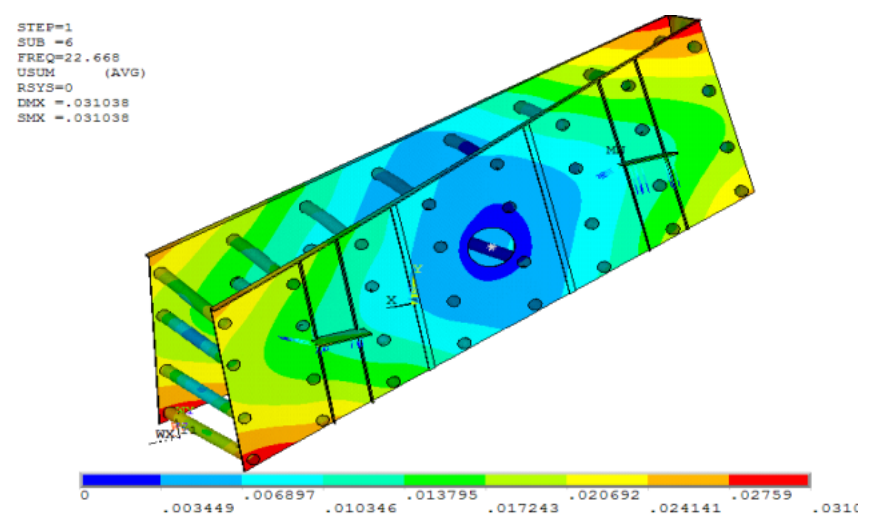

Fig. (9). Sixth vibrating mode.

\section{Results of Dynamic Response Before and After Model Modification}

Extracting the dynamic response chart and displacement chart of vibrating screen under working frequency of $16.7 \mathrm{~Hz}$, the dynamic stress of screen box is $34.7 \mathrm{MPa}$ which is more than the allowable stress and concentrates in the central of side plate. After model modification, making the same dynamic analysis under the same conditions, the dynamic response chart and displacement chart are shown in Figs. $(\mathbf{1 0}, \mathbf{1 1})$. The maximum stress of the improved model is $18 \mathrm{MPa}$ and is less than the allowable stress of $24.5 \mathrm{MPa}$. Large displacement also appears in the discharge end under working frequency, and the value decreases to $0.10 \mathrm{~mm}$ from $0.17 \mathrm{~mm}$. In general, stress concentration of vibrating screen improved.

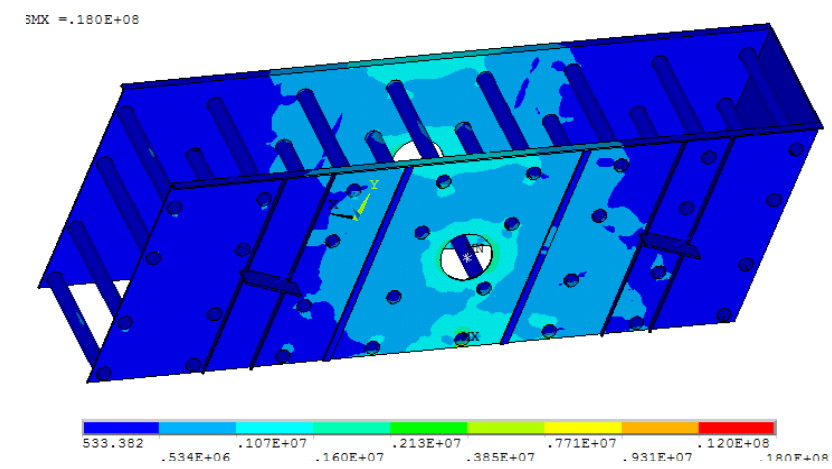

Fig. (10). Model dynamic stress charts.

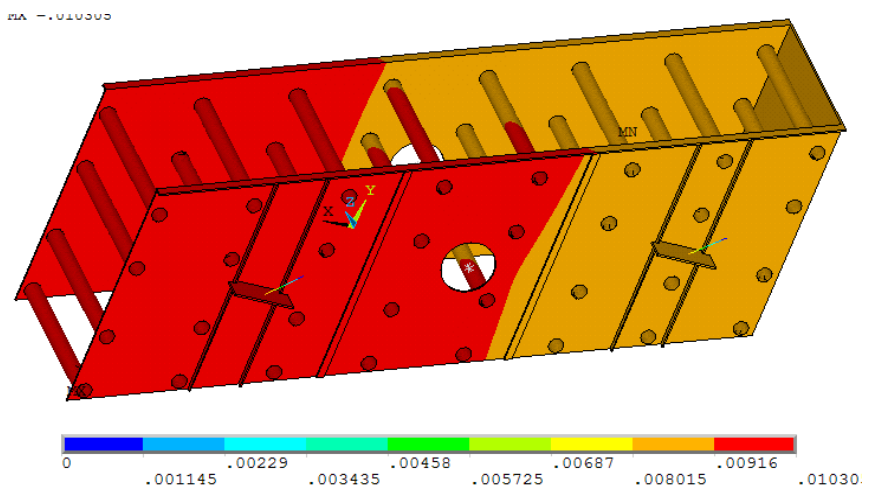

Fig. (11). Displacement charts. 
Table 4. Relevant parameters of circular vibrating screen.

\begin{tabular}{|c|c|c|c|c|c|}
\hline $\begin{array}{c}\text { Optimized } \\
\text { Order }\end{array}$ & $\boldsymbol{f}_{\mathbf{1}} / \mathbf{H z}$ & $\boldsymbol{f}_{\mathbf{2}} / \mathbf{H z}$ & $\boldsymbol{f}_{\mathbf{3}} / \mathbf{H z}$ & $\boldsymbol{m}_{\mathbf{t}} / \mathbf{k g}$ & $\begin{array}{c}\text { Dynamic } \\
\text { Stress } / \mathbf{M P a}\end{array}$ \\
\hline \hline Before & 20.834 & 29.735 & 33.026 & 9870 & 34.7 \\
\hline After & 22.668 & 30.686 & 35.034 & 9515 & 18 \\
\hline Change range/\% & 8.8 & 3.2 & 6.1 & 3.5 & 48 \\
\hline
\end{tabular}

After comparing the parameters of the circular vibrating screen before and after optimization, from the results (as shown in Table 4), it can be observed that the first three frequencies of elastic deformation increased by $8.8 \%, 3.2 \%$ and $6.1 \%$. The dynamic stress decreased by $48 \%$ after optimization. Rigidity of vibrating screen after size optimization improved, elastic deformation of screen body reduced, stress concentration weakened, stress distribution became more uniform and mass of structure decreased. In short, the stability of structure improved while the material and cost were saved.

\section{CONCLUSION}

(1) Using embed analytic sensitivity method by considering sensitivity of variable parameters into size optimization process of the vibrating screen side plate, the calculation efficiency improved and stale optimization results were obtained.

(2) Taking the mass of circular vibrating screen side plate as objective function, the minimum mass of side plate was obtained after meeting multiple frequencies conditions. Single side plate mass decreased by $7.75 \%$ after optimization and the material and cost were saved.

By evaluating vibrating screen after optimization, the mass decreased by $3.5 \%$, frequency of elastic deformation close to working frequency increased by $8.8 \%$, and the dynamic stress reduced by $48 \%$. Natural frequencies were raised, rigidity of plate was improved, stress concentration weakened, mode frequencies were observed to be far away from working frequency and the stability of structure improved.

\section{CONFLICT OF INTEREST}

The authors confirm that this article content has no conflict of interest.

\section{ACKNOWLEDGEMENTS}

The authors would like to thank the support by Natural Science Foundation of China under the Grant 51275210 and 51204181. The authors also thank the support by The Fundamental Research Funds for the Central Universities under the Grant JUSRP11210.

\section{REFERENCES}

[1] E. Sandgren, and T.M. Cameron, "Robust design optimization of structures through consideration of variation", Computers and Structures, vol. 80, pp. 1605-10, 2002.

[2] L. Hui-bin, Vibration theory and engineering application. Beijing Institute of Technology Press: Beijing, pp. 235-48, 2006.

[3] H. Xiao-mei, L. Chu-sheng, and Z. Cheng-yong, "Optimal design of large vibrating screen based on multiple frequencies constraints and analytical sensitivity methods", Journal of Central South University(Science and Technology), vol. 42, pp. 664-670, 2011.

[4] Z. Yang, "Dynamic analysis and structure optimization design of 4YK1860 vibration screen”, M.S.thesis, China University of Mining and Technology, Xuzhou, China, 2011.

[5] E. Taroco, and R. A. Feijoo, "A unified approach for shape sensitivity analysis of elastic shells", Structural and Multidisciplinary Optimization, vol. 27, pp. 66-79, 2004.

[6] C.K. Park, W. J. Kim, and S. Lee, "Positive sensitivity analysis in linear programming", Asia-Pacific Journal of Operational Research, vol. 21, pp. 53-68, 2004.

[7] L. Xing-pei, and C. Chang-bing, "Designing method and engineering application on optimization of frequency constraint", Journal of Machine Design, vol. 23, pp. 36-38, 2006.

[8] M.A. Fu-qiang, "Dynamic characteristics analysis of vibrating screen", Mining and Processing Equipment, vol. 24, pp. 40,1996.

[9] C. Jin, Z. Ze-peng, "Optimization design research on bridge construction under frequencies constraints", Central South Highway Engineering, vol. 26, pp. 67-9, 2001

[10] W. Rong-chang, Y. Jia-nian, W. Wen-liang, "Sensitivity analysis for structural optimal design", Journal of Vibration and Shock, vol.15, pp. 1-4, 1996.

[11] R. Grandh, "Structural optimization with frequency constrains: A review", AIAA Journal, vol. 31, no. 12, pp. 2296-304, 1993.

[12] N. S. Khot, "Optimization of structures with multiple frequency constraints", Computers and Structures, vol. 20, pp. 869-76, 1985. 